\title{
Effect of L. usitatissimum (Flaxseed/Linseed) Fixed Oil against Distinct Phases of Inflammation
}

\author{
Gaurav Kaithwas ${ }^{1,2}$ and Dipak K. Majumdar ${ }^{3}$ \\ ${ }^{1}$ Department of Pharmaceutical Sciences, Babasaheb Bhimrao Ambedkar University, Raebareli Road, Vidyavihar, \\ Lucknow, Uttar Pradesh 226 025, India \\ ${ }^{2}$ Department of Pharmaceutical Sciences, Faculty of Health and Medical Sciences, Allahabad Agricultural Institute-Deemed University, \\ Allahabad, Uttar Pradesh 211 007, India \\ ${ }^{3}$ Delhi Institute of Pharmaceutical Sciences and Research, (Formerly College of Pharmacy), University of Delhi, Sector III Pushp Vihar, \\ New Delhi, Delhi 110 017, India
}

Correspondence should be addressed to Dipak K. Majumdar; dkmajumdaar@yahoo.com

Received 18 December 2012; Accepted 10 January 2013

Academic Editors: A. Jalili, B. Kim, and D. Szukiewicz

Copyright (C) 2013 G. Kaithwas and D. K. Majumdar. This is an open access article distributed under the Creative Commons Attribution License, which permits unrestricted use, distribution, and reproduction in any medium, provided the original work is properly cited.

\begin{abstract}
The present investigation summarizes the effect of Linum usitatissimum fixed oil against different phases of acute inflammatory reaction, namely, protein exudation, peritoneal capillary permeability, and leukocyte migration. The fixed oil exhibited dosedependent inhibition of protein exudation vascular permeability, comparable to standard aspirin. The oil also inhibited the leukocyte migration in pleural exudates in a dose-dependent manner. Production of less vasodilatory $\left(\mathrm{PGE}_{3}\right)$ and chemotactic $\left(\mathrm{LTB}_{5}\right)$ eicosanoids through EPA (derived from linolenic acid) metabolism could account for the above observations.
\end{abstract}

\section{Introduction}

Linum usitatissimum L, (also known as common flax or linseed) an annual herb believed to have originated in Egypt, is a member of the genus Linum in the family Linaceae. The seeds produce a fixed oil known as linseed oil or flaxseed oil. It is one of the oldest commercial oils, and solvent processed flaxseed oil has been used for centuries as a drying oil in painting and varnishing. Raw oil is used as an astringent in fungicidal lotion and as an insecticide and has moderate insect repellent properties [1]. The oil contains unsaturated fatty acids like oleic acid (12-30\%), linoleic acid (8-29\%), and linolenic acid (35-67\%) [2]. These fatty acids appear to render drying property to the oil. In earlier studies, the L. usitatissimum fixed oil has been reported to exhibit significant anti-inflammatory [3], antiarthritic [4], antiulcer [5], and antidiabetic [6] properties along with the efficacy against experimental esophagitis in experimental animals [7]. The antimicrobial activity of L. usitatissimum oil and its therapeutic efficacy in bovine mastitis, an inflammatory disorder caused by microbial infection, has been reported recently [8]. Considering the significant anti-inflammatory and antiarthritic activity, the present study has been undertaken to evaluate the possible effect of fixed oil against distinct phases of inflammation using suitable animal models.

\section{Materials and Methods}

\subsection{Materials}

2.1.1. Plant Material. Flaxseed/linseed (Variety: JL-59) was obtained from The Division of Seed Science, Department of Agronomy, Allahabad Agricultural Institute-Deemed University (AAI-DU), Allahabad, India. The seeds were authenticated at The National Botanical Research Institute (NBRI, CSIR), Lucknow, India, and the voucher sample was deposited at NBRI.

2.1.2. Extraction of Oil. Seeds were crushed and cold macerated in petroleum ether $\left(40-60^{\circ} \mathrm{C}\right)$ for 7 days. Petroleum ether was evaporated from the extract, and the oil was filtered to clarity. The oil was stored at room temperature in amber 
colored airtight bottle. To avoid oxidation, the oil was purged with nitrogen and was filled to the brim of the bottle so that there was no headspace. The yield of fixed oil was $17.50 \%$ v/w with reference to dried seeds. The density of the oil was $0.952 \mathrm{~g} / \mathrm{mL}$. Gas chromatographic analysis (Agilent GC make 6890; column: DBFFAP, dimension (30 $\mathrm{M} \times 0.53 \mathrm{~mm} \times$ $1.0 \mu \mathrm{m}$ ) using flame ionization detector; carrier gas: nitrogen; volume of injection $1 \mu \mathrm{L}$; internal standard: cetyl alcohol) of the methyl ester of oil revealed the presence of palmitic acid (5.53\%), stearic acid (4.67\%), oleic acid (19.05\%), linoleic acid (13.67\%), and linolenic acid (57.38\%). The oil thus obtained was subjected to further studies.

2.1.3. Animals. Wistar strains of albino rats $(100-150 \mathrm{~g})$ and Swiss strain of albino mice (25-50 g) were obtained from The Central Animal House, Department of Animal Husbandry, Allahabad Agricultural Institute-Deemed University. The animals were housed under standard conditions of temperature $\left(25 \pm 1^{\circ} \mathrm{C}\right)$ with $12 \mathrm{~h}$ light/dark cycle and had free access to commercial pellet diet and water. The animals were given week's time to get acclimatized to the laboratory condition, before experimentation. All experiments were performed according to the CPCSEA guidelines for the laboratory animals and ethics, Department of Animal Welfare, Government of India.

2.1.4. Drugs and Chemicals. Pentobarbitone was purchased from Sigma-Aldrich, USA, and chlorpromazine (Megatil) was procured from Intas Pharmaceuticals Ltd., India. Aspirin and phenylbutazone were received as a generous gift samples from Arbro Pharmaceuticals Ltd., New Delhi, India. All other chemicals were of analytical grade.

\subsection{Methods}

2.2.1. Inflammatory Exudation (Protein Exudation). Group of albino mice were treated either with $L$. usitatissimum fixed oil (1-3 mL/kg) or control vehicle (distilled water, $3 \mathrm{~mL} / \mathrm{kg}$ ) or standard drug (aspirin, $100 \mathrm{mg} / \mathrm{kg}$ ) intraperitoneally. After $30 \mathrm{~min}, 0.25 \mathrm{~mL}$ of $1.2 \%$ acetic acid was administered i.p. to each mouse. After $3 \mathrm{~h}$, viscera's were exposed by abdominal incision; abdomen was irrigated with physiological saline containing $0.1 \mathrm{mM}$ disodium EDTA. The pooled washing was made to $6 \mathrm{~mL}$ with physiological saline and then centrifuged. Total amount of protein in the supernatant was estimated with Folin's reagent [9].

2.2.2. Peritoneal Capillary Permeability (Dye Leakage Method). L. usitatissimum fixed oil $(1-3 \mathrm{~mL} / \mathrm{kg})$ or control vehicle (distilled water, $3 \mathrm{~mL} / \mathrm{kg}$ ) or standard drug (aspirin, $100 \mathrm{mg} / \mathrm{kg}$ ) was administered intraperitoneally to group of albino mice $(n=6)$, and after $3 \mathrm{~h}$, each mouse received $4 \mathrm{~mL}$ of $0.05 \mathrm{~N}$ acetic acid in $0.9 \%$ saline i.p. followed by immediate i.v. administration of $0.1 \mathrm{~mL}$ of $4 \%$ pontamine sky blue (dye). One hour after the administration of the dye, animals were sacrificed by cervical dislocation and the peritoneal cavity was drained. The collected exudate was centrifuged for $10 \mathrm{~min}$, at $2000 \mathrm{rpm}$, and $0.5 \mathrm{~mL}$ of the supernatant was diluted with $4.5 \mathrm{~mL}$ of physiological saline. Absorbance of the diluted supernatant was measured in a colorimeter at $625 \mathrm{~nm}$ using normal saline as blank. The mean percentage of the light absorption was then calculated for both control and drugtreated groups [10].

2.2.3. Leucocyte Migration. Carrageenan $(0.1 \mathrm{~mL}$ of $1 \%$ aqueous suspension) was injected into the pleural cavity of anesthetized rats as described previously [11], pretreated i.p. 30 min earlier with L. usitatissimum fixed oil (1-3 mL/kg) or control vehicle (distilled water, $3 \mathrm{~mL} / \mathrm{kg}$ ) or standard drug (phenylbutazone, $100 \mathrm{mg} / \mathrm{kg}$ ). After $5 \mathrm{~h}$, the animals were sacrificed and $2 \mathrm{~mL}$ of Hank's solution [12] was injected into the pleural cavity. The animals were then rocked to allow the mixing of the solution with the exudates, which was then collected with a pipette. The total number of leucocytes present in the exudate was counted with a haemocytometer [13].

2.2.4. Statistical Analysis. All the data are presented as mean \pm SEM and analyzed by one-way ANOVA followed by Dunnett's test for the possible significance identification between the various groups. $P<0.05$ was considered statistically significant. Statistical analysis was carried out using Graph padprism 3.0 (Graph pad software, San Diego, CA).

\section{Results and Discussion}

L. usitatissimum fixed oil demonstrated a significant $(P<$ 0.05) dose-dependent inhibition of protein exudation (i.e., rise in protein concentration in peritoneal fluid) and inhibited the vascular permeability evidenced by inhibition to dye leakage. Degree of inhibition of protein exudation and vascular permeability was comparable to standard aspirin (Table 1). Similarly, in carrageenan-induced pleurisy in rats, L. usitatissimum fixed oil demonstrated a significant $(P<0.05)$ dosedependent inhibition in leucocyte migration in pleural exudates and slightly better results were observed at a dose level of $3 \mathrm{~mL} / \mathrm{kg}$ (i.p.), in comparison to phenylbutazone (Table 2).

The present investigation revealed the effect of $L$. usitatissimum fixed oil on distinct phases of inflammatory process: firstly an acute phase of local vasodilatation and increased capillary permeability leading to exudation, followed by leucocytes migration. The momentous characteristic of the inflammatory reaction is the transient increase in permeability of small blood vessels to proteins, initially involving the venules, whereas the delayed phase of increased permeability involves the capillaries as well, and is more relevant to chronic inflammation [14]. The effect of L. usitatissimum fixed oil on the intensity of peritoneal inflammation was evaluated by direct measurement of exuded plasma protein using Folin's reagent [9] and leakage of protein bound dye into the peritoneal cavity [10]. L. usitatissimum fixed oil significantly reduced the peritoneal vascular permeability, indicating the suppression of the vascular response in the process of acute inflammation. Anti-inflammatory potential was further confirmed by inhibition of carrageenan-induced pleurisy in rats, as L. usitatissimum fixed oil significantly inhibited the migration of leucocytes in pleural exudates. The key inflammatory mediators are the $n-6$ eicosanoids, prostaglandin $\mathrm{E}_{2}\left(\mathrm{PGE}_{2}\right)$, and leukotriene $\mathrm{B}_{4}\left(\mathrm{LTB}_{4}\right)$ which 
TABLE 1: Effect of L. usitatissimum fixed oil and aspirin on acetic acid induced peritoneal inflammation and peritoneal capillary permeability in mice.

\begin{tabular}{lcccc}
\hline Serial number & Treatment & Dose & $\begin{array}{c}\text { Total amount of protein }(\mathrm{mg} / \mathrm{mL}) \text { exudation } \\
3 \mathrm{~h} \text { after acetic acid administration } \\
(0.25 \mathrm{~mL} \text { of } 1.2 \%, \mathrm{i} . \mathrm{p} .)\end{array}$ & \begin{tabular}{c} 
Absorbance at $625 \mathrm{~nm}$ \\
\hline 1
\end{tabular} \\
\hline & Control (distilled water) & $3 \mathrm{~mL} / \mathrm{kg}$ & $5.01 \pm 0.21$ & $0.49 \pm 0.02$ \\
3 & L. usitatissimum fixed oil & $1 \mathrm{~mL} / \mathrm{kg}$ & $4.15 \pm 0.24^{*}(17.17)$ & $0.31 \pm 0.03^{*}(36.73)$ \\
4 & L. usitatissimum fixed oil & $2 \mathrm{~mL} / \mathrm{kg}$ & $2.82 \pm 0.21^{*}(43.71)$ & $0.19 \pm 0.05^{*}(61.22)$ \\
5 & L. usitatissimum fixed oil & $3 \mathrm{~mL} / \mathrm{kg}$ & $1.59 \pm 0.18^{*}(68.26)$ & $0.20 \pm 0.03^{*}(59.18)$ \\
\hline
\end{tabular}

Values in parenthesis represent percentage inhibition (values are mean \pm SEM).

Each group contains six animals; all groups were compared to the group 1 by Dunnett's test $\left({ }^{*} P<0.05\right)$.

TABLE 2: Effect of L. usitatissimum fixed oil and phenylbutazone on carrageenan-induced pleurisy (leucocytes migration) in albino rats.

\begin{tabular}{lccc}
\hline Serial number & Treatment & Dose & Number of leucocytes $\left(\times 10^{3} / \mathrm{mm}^{3}\right)$ \\
\hline 1 & Control (distilled water) & $3 \mathrm{~mL} / \mathrm{kg}$ & $8854.25 \pm 112.21$ \\
2 & L. usitatissimum fixed oil & $1 \mathrm{~mL} / \mathrm{kg}$ & $6524.24 \pm 302.14^{*}(26.31)$ \\
3 & L. usitatissimum fixed oil & $2 \mathrm{~mL} / \mathrm{kg}$ & $3954.25 \pm 124.25^{*}(55.34)$ \\
4 & L. usitatissimum fixed oil & $3 \mathrm{~mL} / \mathrm{kg}$ & $3548.45 \pm 258.26^{*}(59.92)$ \\
5 & Aspirin & $100 \mathrm{mg} / \mathrm{kg}$ & $3654.88 \pm 222.45^{*}(58.72)$ \\
\hline
\end{tabular}

Values in parenthesis represent percentage inhibition (values are mean \pm SEM); each group contains six animals; all groups were compared to the control by Dunnett's test $\left({ }^{*} P<0.05\right)$.

are derived from polyunsaturated fatty acid arachidonic acid (AA; $20: 4, n-6)$ [15] by the action of cyclooxygenase and lipoxygenase. $\mathrm{PGE}_{2}$ is a potent vasodilator, whereas $\mathrm{LTB}_{4}$ is a powerful chemotactic agent. $\mathrm{PGE}_{2}$ does not increase the permeability of postcapillary venules but potentiates the effect of histamine and bradykinin to increase permeability. $\mathrm{PGE}_{2}$ also potentiates the effect of bradykinin by sensitising afferent $C$ fibres to increase pain [16]. On the other side, leukotriene $\left(\mathrm{LTB}_{4}\right)$ is a potent chemotactic agent for both neutrophils and macrophages. $\mathrm{LTB}_{4}$ binds to its specific surface cell receptors (BLT-1 and BLT-2) and stimulates a number of leukocyte functions, that is, adhesion of neutrophils to vascular endothelium, transendothelial migration, and chemotaxis $[17,18]$. Vasodilation and increased capillary permeability permits fluids and large molecules to leave the blood stream and increased movement of leucocytes into the surrounding tissues by diapedesis. Thus, $\mathrm{PGE}_{2}$ and $\mathrm{LTB}_{4}$ together can cause/promote vascular leakage and extravagation of fluids and are significantly involved in the physiology of acute inflammation [15].

The anti-inflammatory activity of various plant lipids has been reported, and the results revealed that the lipids containing $\alpha$-linolenic acid (ALA, 18:3, n-3), for example, linseed oil, $O$. sanctum fixed oil, and soyabean oil had a significant anti-inflammatory activity. Subsequently, methyl esters of various fatty acids, namely, oleic acid, linoleic acid, and ALA, were tested against $\mathrm{PGE}_{2}{ }^{-}, \mathrm{LTB}_{4}$, and arachidonic acid-induced paw oedema in rats, where only ALA showed a significant oedema inhibition against all the inflammatory mediators suggesting the ALA as a dual inhibitor of arachidonate metabolism [19]. Previously, we also observed antiarthritic activity of the L. usitatissimum fixed oil against turpentine oil-induced joint oedema, formaldehyde-induced and adjuvant-induced arthritis in albino rats [4]. ALA (18:3, $n$-3) is a precursor for eicosapentaenoic acid (EPA, 20:5, $n-3)$, which competes with AA $(20: 4, n-6$, precursor for lipid mediators of inflammation) for cyclooxygenase and lipoxygenase pathway. EPA by acting as a substrate for cyclooxygenase and lipoxygenase pathway produces $\mathrm{PGE}_{3}$ (less potent vasodilator than $\left.\mathrm{PGE}_{2}\right)$ [20] and $\mathrm{LTB}_{5}(100$ times less potent chemotactic than $\mathrm{LTB}_{4}$ ) [21-23]. Thus, less vasodilatory $\left(\mathrm{PGE}_{3}\right)$ and chemotactic $\left(\mathrm{LTB}_{5}\right)$ response of lipid mediators derived from EPA (metabolic product of ALA metabolism) accounts for the inhibition of fluid and protein exudation along with diminished leucocytes migration observed in the present experiment.

\section{Conflict of Interests}

The authors declare that they have no conflict of interests.

\section{Acknowledgment}

The authors are thankful to Arbro Pharmaceuticals Limited (New Delhi, India) for providing the drugs mentioned in the paper as a generous gift sample.

\section{References}

[1] The Wealth of India, A Dictionary of Indian Raw Materials and Industrial Products, vol. 4 of 1st supplement series, National Institute of Science Communication and Information Resources, CSIR, New Delhi, India, 2006.

[2] The Wealth of India, Industrial Products, Part IX, Publications and Information Directorate, CSIR, 1976.

[3] G. Kaithwas, A. Mukherjee, A. K. Chaurasia, and D. K. Majumdar, "Antiinflammatory, analgesic and antipyretic activities of 
L. usitatissimum (flaxseed/linseed) fixed oil," Indian Journal of Experimental Biology, vol. 49, no. 12, pp. 932-938, 2011.

[4] G. Kaithwas and D. K. Majumdar, "Therapeutic effect of Linum usitatissimum (flaxseed/linseed) fixed oil on acute and chronic arthritic models in albino rats," Inflammopharmacology, vol. 18, no. 3, pp. 127-136, 2010.

[5] G. Kaithwas and D. K. Majumdar, "Evaluation of antiulcer and antisecretory potential of Linum usitatissimum fixed oil and possible mechanism of action," Inflammopharmacology, vol. 18, no. 3, pp. 137-145, 2010.

[6] G. Kaithwas and D. K. Majumdar, "In vitro antioxidant and in vivo antidiabetic, antihyperlipidemic activity of linseed oil against streptozotocin-induced toxicity in albino rats," European Journal of Lipid Science and Technology, vol. 144, no. 11, pp. 1237-1245, 2012.

[7] N. Renu, G. Kaithwas, P. W. Ramteke, and S. A. Saraf, "Effect of Linum usitatissimum (Linseed/Flaxseed) fixed oil on experimental esophagitis in elbino rats," Acta Gastro-Enterologica Belgica, vol. 75, pp. 331-335, 2012.

[8] G. Kaithwas, A. Mukerjee, P. Kumar, and D. K. Majumdar, "Linum usitatissimum (linseed/flaxseed) fixed oil: antimicrobial activity and efficacy in bovine mastitis," Inflammopharmacology, vol. 19, no. 1, pp. 45-52, 2011.

[9] O. H. Lowry, N. J. Rosebrough, A. L. Farr, and R. J. Randall, "Protein measurement with the Folin phenol reagent," The Journal of Biological Chemistry, vol. 193, no. 1, pp. 265-275, 1951.

[10] R. B. Filderman and B. A. Kovacs, "Anti-inflammatory activity of the steroid alkaloid glycoside, toatine," British Journal of Pharmacology, vol. 37, no. 3, pp. 748-755, 1969.

[11] S. C. R. Meacock and E. A. Kitchen, "Effects of the non-steroidal anti-inflammatory drug benoxaprofen on leucocyte migration," Journal of Pharmacy and Pharmacology, vol. 31, no. 6, pp. 366370, 1979.

[12] R. Cruickshank, Medical Microbiology, ELBS, London, UK, 1965.

[13] M. Di Rosa, J. P. Giroud, and D. A. Willoughby, "Studies on the mediators of the acute inflammatory response induced in rats in different sites by carrageenan and turpentine," Journal of Pathology, vol. 104, no. 1, pp. 15-29, 1971.

[14] K. F. Swingle, "Evaluation for antiinflammatory activity," in Antiinflammatory Agents: Chemistry Pharmacology, R. A. Scherrer and M. W. Whitehouse, Eds., vol. 2, pp. 33-122, Academic Press, New York, NY, USA, 1974.

[15] B. Henderson, E. R. Pettipher, and G. A. Higgs, "Mediators of rheumatoid arthritis," British Medical Bulletin, vol. 43, no. 2, pp. 415-428, 1987.

[16] H. P. Rang, M. M. Dale, J. M. Ritter, and P. K. Moore, Pharmacology, Churchill Livingstone, Edinburgh, Scotland, 5th edition, 2003.

[17] T. Yokomizo, T. Izumi, K. Chang, Y. Takuwa, and T. Shimizu, "A G-protein-coupled receptor for leukotriene B4 that mediates chemotaxis," Nature, vol. 387, no. 6633, pp. 620-624, 1997.

[18] T. Yokomizo, K. Kato, K. Terawaki, T. Izumi, and T. Shimizu, "A second leukotriene B4receptor, BLT2: a new therapeutic target in inflammation and immunological disorders," Journal of Experimental Medicine, vol. 192, no. 3, pp. 421-431, 2000.

[19] S. Singh and D. K. Majumdar, "Evaluation of antiinflammatory activity of fatty acids of Ocimum sanctum fixed oil," Indian Journal of Experimental Biology, vol. 35, no. 4, pp. 380-383, 1997.

[20] J. S. Hawkes, M. J. James, and L. G. Cleland, "Separation and quantification of PGE3 following derivatization with panacyl bromide by high pressure liquid chromatography with fluorometric detection," Prostaglandins, vol. 42, no. 4, pp. 355-368, 1991.

[21] M. J. James, R. A. Gibson, and L. G. Cleland, "Dietary polyunsaturated fatty acids and inflammatory mediator production," The American Journal of Clinical Nutrition, vol. 71, no. 1, pp. 343S348S, 2000.

[22] T. H. Lee, J. M. Menica-Huerta, C. Shih, E. J. Corey, R. A. Lewis, and K. F. Austem, "Characterization of biologic properties of 5,12 - dihydroxy derivative of eicosapentaenoic acid, including leukotriene B5 and double lipoxygenase product," The Journal of Biological Chemistry, vol. 259, no. 4, pp. 2383-2389, 1984.

[23] D. W. Goldman, W. C. Pickett, and E. J. Goetzl, "Human neurtrophil chemotactic and degranulating activites of leukotriene B5 (LTB5) derived from eicosapentaenoic acid," Biochemical and Biophysical Research Communications, vol. 117, no. 1, pp. 282-288, 1983. 


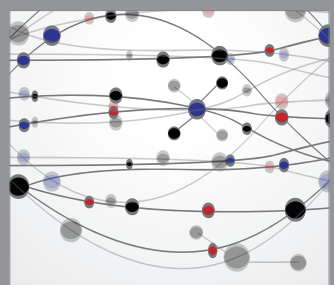

The Scientific World Journal
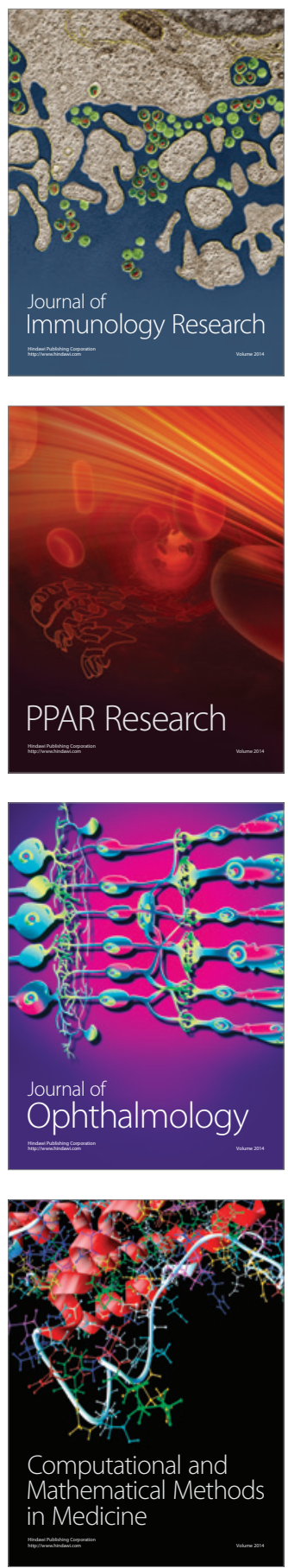

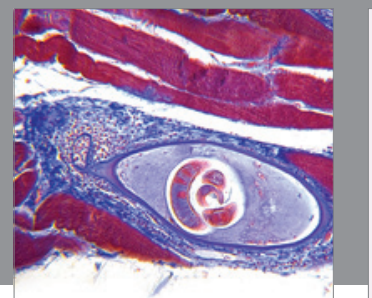

Gastroenterology

Research and Practice
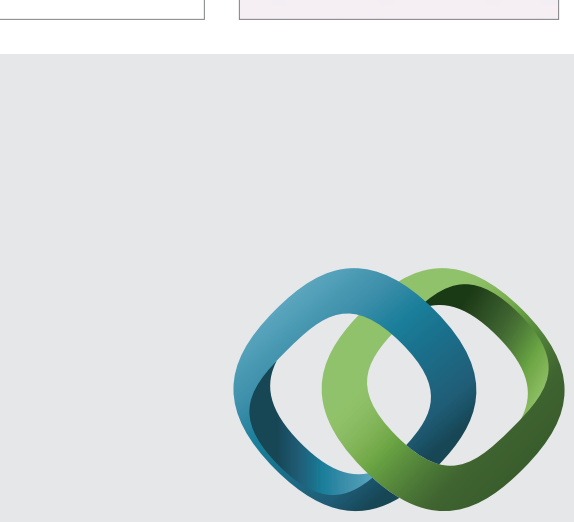

\section{Hindawi}

Submit your manuscripts at

http://www.hindawi.com
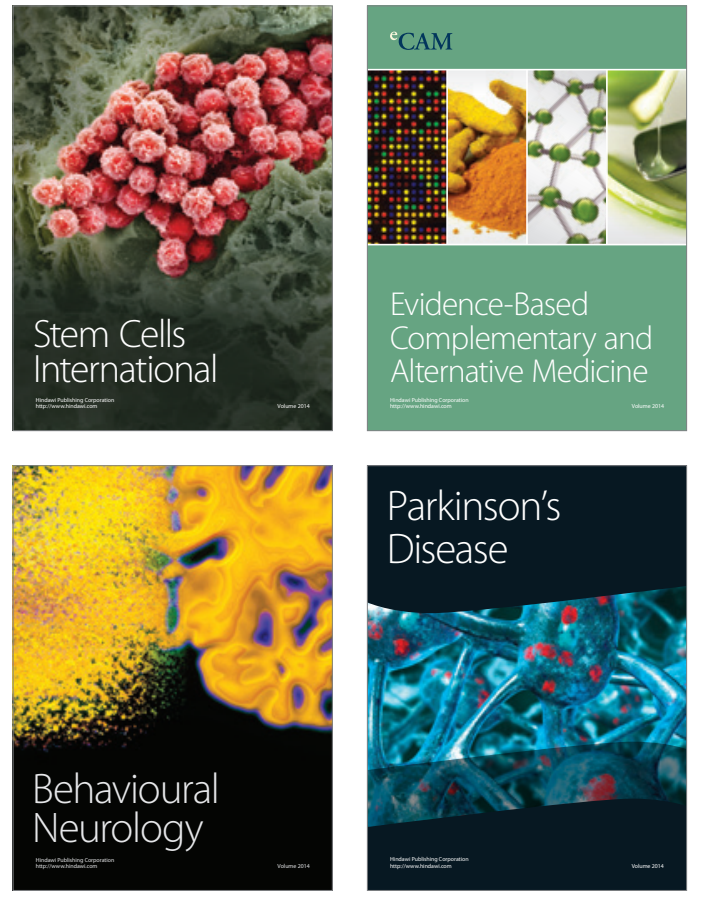
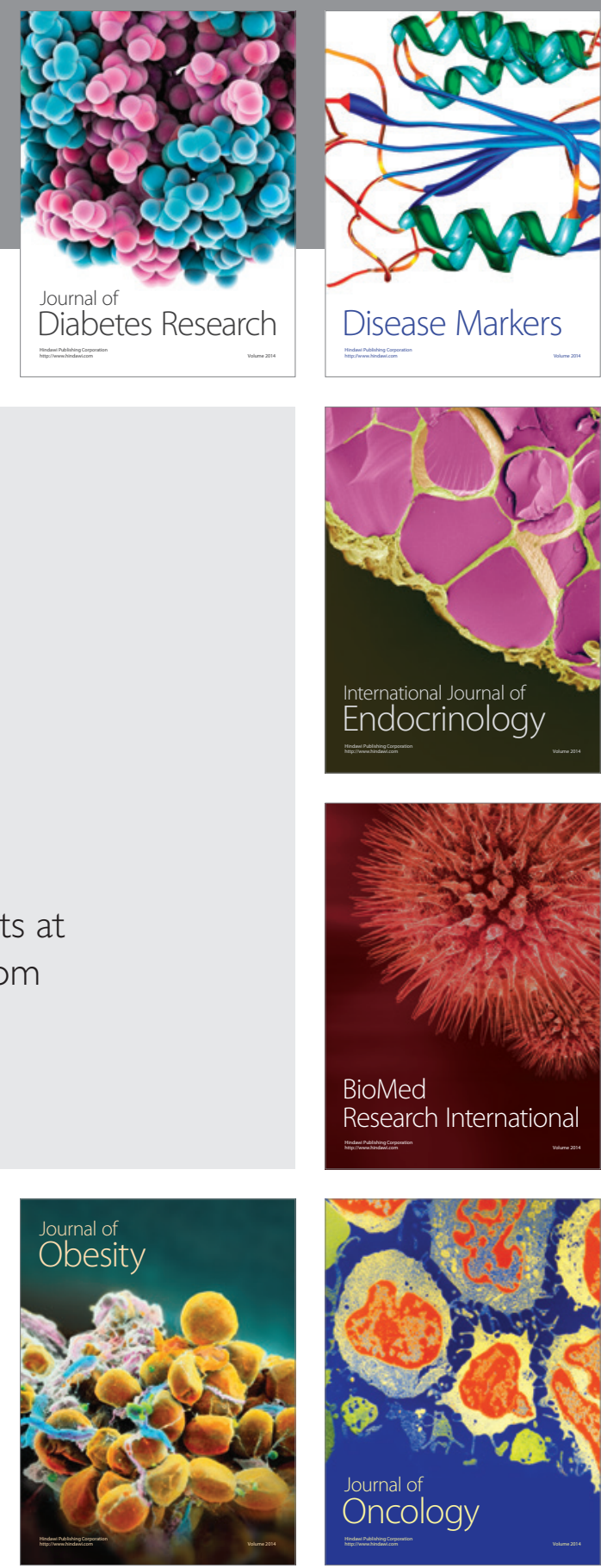

Disease Markers
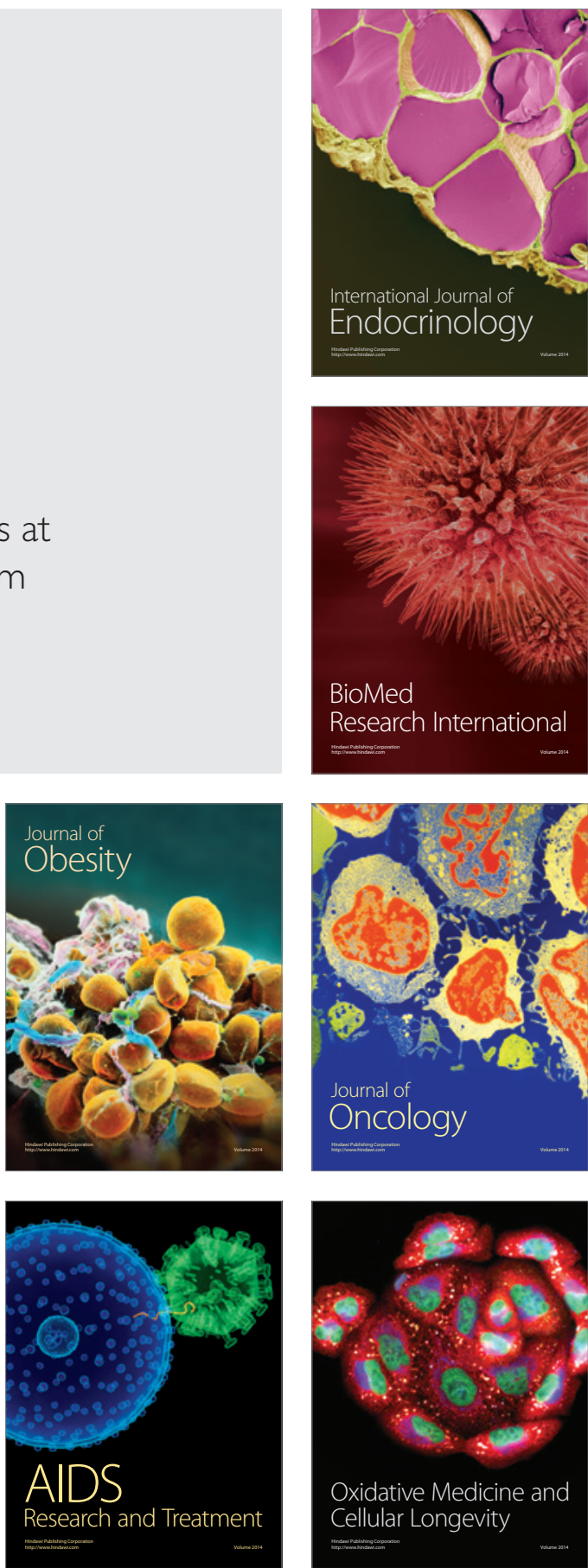